\title{
PROBLEMATIKA DI AKHIR KEHIDUPAN PASIEN DEMENSIA BERAT
}

\author{
END-OF-LIFE ISSUES IN ADVANCED DEMENTIA
}

Diatri Lastri Nari*

\begin{abstract}
The number of people living with dementia worldwide in 2015 was estimated at 47.47 million, reaching 75.63 million in 2030. Dementia could cause many issues such as establishing goals of care, feeding difficulty, swallowing difficulty, dehydration, pneumonia, and decision making when the patient cannot actively participate. Goals of care for patient with severe dementia are person-centered. To keep hydration and nutrition status in patients with severe dementia, the best approach is risk-managed eating or comfort feeding. The main consideration for antibiotic use in dementia patient with pneumonia is goals of care. In a decision-making discussion, physician should prepare to promote compassionate and evidence-based counselling to minimize the burden of decision making for the surrogate decision maker.
\end{abstract}

Keywords: Advanced dementia, goals of care, decision making, feeding and swallowing difficulty

\section{ABSTRAK}

Jumlah penderita demensia di dunia pada tahun 2015 diperkirakan mencapai 47,47 juta jiwa dan akan mencapai 75,63 juta jiwa pada tahun 2030. Demensia dapat menimbulkan berbagai masalah, seperti kesulitan menentukan tujuan perawatan, masalah terkait perawatan (sulit makan, sulit menelan, dehidrasi, dan pneumonia), serta pengambilan keputusan ketika pasien tidak dapat lagi berpartisipasi secara aktif. Tujuan perawatan pada pasien demensia berat haruslah berpusat pada pasien. Untuk menjaga status hidrasi dan nutrisi pada pasien demensia berat yang kesulitan menelan atau makan, pendekatan yang paling baik adalah risk-managed eating atau comfort feeding. Demikian pula pertimbangan utama penggunaan antibiotik pada pasien demensia. Dalam diskusi mengenai keputusan yang akan diambil, dokter sebaiknya menyiapkan konseling dengan empati dan berdasarkan bukti ilmiah untuk meminimalisasi beban pengambilan keputusan oleh pengganti pengambil keputusan (surrogate decision-maker).

Kata kunci: Demensia berat, pengambilan keputusan, kesulitan makan dan menelan

*Departemen Neurologi FK Universitas Indonesia/RSUP Dr. Cipto Mangunkusumo, Jakarta. Korespondensi: diatri.neurologi@gmail.com.

\section{PENDAHULUAN}

Seiring dengan peningkatan pembangunan kesehatan di Indonesia, usia harapan hidup penduduk Indonesia juga mengalami peningkatan. Usia harapan hidup penduduk Indonesia meningkat dari 68,6 tahun pada tahun 2004 menjadi 72 tahun pada tahun 2015. ${ }^{1}$ Hal ini diperkirakan akan terus bertambah yang akan disertai dengan berbagai macam penyakit degeneratif, terutama demensia.

Jumlah penderita demensia di dunia pada tahun 2015 diperkirakan mencapai 47,47 juta jiwa dan akan mencapai 75,63 juta jiwa pada tahun $2030 .{ }^{2}$ Insiden ini meningkat secara eksponensial dengan pertambahan usia, dua kali lipat setiap pertambahan usia 5,9 tahun dari 3,1/1000 person years pada usia 60-64 tahun menjadi 175/1000 person years pada usia $>95$ tahun. ${ }^{2}$ Sampai saat ini, belum ada data penelitian nasional mengenai prevalensi demensia di Indonesia.

Demensia dapat menimbulkan berbagai masalah, seperti kesulitan menentukan tujuan perawatan, masalah terkait perawatan seperti sulit makan, sulit menelan, dehidrasi, dan pneumonia, serta pengambilan keputusan ketika pasien tidak dapat lagi berpartisipasi secara aktif. ${ }^{3}$ Oleh karena itu perlu diketahui isu-isu mengenai end-of-life pada pasien demensia, sebagai panduan dalam melakukan perawatan dan edukasi kepada keluarga dan pelaku rawat (caregiver).

\section{PEMBAHASAN}

Orang dengan demensia berat kerap "berteman" dengan gangguan metabolik karena kurangnya asupan dan infeksi berulang. Walaupun demikian, perawatan di RS yang diikuti intervensi maksimal, seperti pemberian antibiotik, pemasangan oksigen, jalur intravena, dan pipa nasogaster tidak juga memberikan hasil yang optimal. Hal ini yang menjadi dilema perlu tidaknya agresivitas tata laksana pada demensia berat. Di negara maju, sekitar $67 \%$ orang dengan demensia berat meninggal di nursing home, sedangkan $71 \%$ meninggal dalam enam bulan setelah dimasukan ke nursing home, dan hanya $11 \%$ yang dirujuk ke hospice. ${ }^{3}$ 
Oleh karena itu, pasien demensia sejak derajat paling awal perlu mendapat penjelasan mengenai kemungkinan masalah kesehatan yang akan dihadapinya. Diharapkan pasien dapat memutuskan perlu tidaknya bantuan hidup maksimal, sehingga beban keluarga akan lebih ringan dalam mengambil keputusan pada saat pasien sudah tidak dapat mengambil keputusan sendiri.

\section{Tujuan Perawatan}

Tujuan perawatan pada pasien demensia berat berpusat pada pasien. Perlu pendekatan budaya untuk menyediakan perawatan yang sesuai dengan kebutuhan pasien dan menghormati preferensi pasien dalam pemilihan terapi. Tujuan ini hendaknya dikomunikasikan antara tim tenaga medis, pasien, dan keluarga pasien, sehingga semua pelaku rawat paham perawatan optimal yang dapat diusahakan. ${ }^{4}$

Selama perawatan paliatif, pasien sering mendapat terapi sementara untuk penyakit komorbid yang menyertainya, seperti infeksi saluran kencing, pneumonia, atau gagal jantung untuk membuat pasien merasa lebih nyaman. Dengan demensia yang bertambah berat, fokus utama perawatan pasien perlahan berpindah dari meningkatkan kualitas kehidupan menjadi meningkatkan kualitas kematian. Hingga pada suatu titik, pengobatan yang memiliki efek samping memperpanjang usia tidak lagi tepat secara moral.

\section{Gangguan Makan dan Minum pada Pasien Demensia}

Pasien demensia berat dapat mengalami halhal yang menyebabkan gangguan makan (Tabel 1). ${ }^{5}$

Tabel 1. Gangguan pada Pasien Demensia Berat dan Dampaknya

\begin{tabular}{ll}
\hline \multicolumn{1}{c}{ Jenis Gangguan } & \multicolumn{1}{c}{ Dampak } \\
\hline Gangguan memori & Lupa kapan terakhir makan \\
Gangguan persepsi & $\begin{array}{l}\text { Kesulitan mengenali makanan } \\
\text { dan alat makan }\end{array}$ \\
dan spasial & $\begin{array}{l}\text { Kesulitan untuk melakukan } \\
\text { gerakan }\end{array}$ \\
Disfungsi eksekutif & $\begin{array}{l}\text { Tidak sesuainya jam makan pasien } \\
\text { dengan orang sekitarnya }\end{array}$ \\
& $\begin{array}{l}\text { Kesulitan memahami instruksi } \\
\text { jam makan dan mengartikulasikan } \\
\text { makanan kesukaannya }\end{array}$ \\
\hline
\end{tabular}

Pasien demensia berat yang mengalami kesulitan makan atau menelan, tidak jarang harus dirawat di RS hingga hidrasi dan nutrisinya terjaga dengan baik. Pasien-pasien yang berisiko aspirasi biasanya dipasangkan jalur nutrisi artifisial seperti nasogastric-tube (NGT) atau percutaneous endoscopic gastrostomy tube (PEG). Namun pembuktian ilmiahnya masih terbatas. ${ }^{5}$ Penggunaan jalur nutrisi buatan tersebut masih berisiko aspirasi, dapat menyebabkan mordibitas dari bocor dan rasa tidak nyaman, masih membutuhkan tenaga medis untuk membetulkan posisinya, ${ }^{6-8}$ serta tidak mengurangi mortalitas pasien. ${ }^{9}$

Pasien demensia berat juga sangat mungkin mengalami dehidrasi, namun gejalanya tidak spesifik. Biasanya dehidrasi didiagnosis hanya dari penurunan volume urin yang berkaitan dengan hipernatremia dan uremia. Pasien dapat dipasangkan clysis intravena atau subkutan, suatu infus yang kurang invasif, namun harus tetap diperhatikan kenyamanannya. ${ }^{10}$

Pendekatan yang paling baik untuk menjaga status hidrasi dan nutrisi pasien adalah risk-managed eating atau comfort feeding. ${ }^{5,10}$ Pasien dengan demensia dibantu untuk makan atau minum secara oral sampai pasien merasa kesulitan untuk makan atau minum lagi. Untuk meringankan gejala mulut kering dan haus, dianjurkan perawatan mulut seperti membersihkan mulut dengan swab dan melubrikasi mulut pasien setiap dua jam..$^{5,10}$

\section{Pneumonia}

Pneumonia adalah salah satu penyebab tersering perawatan dan mortalitas pasien demensia berat, bahkan dianggap sebagai "teman bagi orang tua”. Dengan kata lain, pneumonia menjadi salah satu cara pasien meninggal secara alami. ${ }^{11}$ Hal ini sering terjadi pada pasien-pasien yang sudah tidak mampu melakukan aktivitas sehari-hari secara mandiri atau hanya berbaring di kasur dan mengalami disfagia. Penggunaan antibiotik dapat memperpanjang hidup pasien hingga 9 bulan setelah diduga pneumonia. ${ }^{10,12-13}$

Namun semakin agresif tata laksana yang diberikan, seperti penggunaan antibiotik intravena atau perawatan di RS, akan membuat pasien tidak nyaman, sehingga tidak disarankan kecuali diberikan secara oral. ${ }^{12-13}$ 
Terapi simtomatik lain adalah pemberian oksigen, opioid untuk mengontrol nyeri, obat antikolinergik, seperti atropin untuk mengurangi sekresi pernapasan, dan benzodiazepin atau antipsikotik untuk mengurangi nyeri atau agitasi. Namun penggunaan benzodiazepin dapat meningkatkan risiko jatuh sampai fraktur, dan delirium, ${ }^{14-15}$ hingga sebaiknya digunakan obat kerja jangka pendek. ${ }^{16}$

Begitu pula obat-obat antipsikotik pada pasien demensia dapat meningkatkan risiko kejadian serebrovaskular, gejala ekstrapiramidal, penurunan fungsi kognitif, pneumonia, dan jatuh. ${ }^{15}$ American Geriatric Society (AGS) merekomendasikan antipsikotik jika tatalaksana nonfarmakologis telah gagal atau pasien membahayakan dirinya sendiri atau orang lain. ${ }^{17}$ Lebih disarankan penggunaan antipsikotik generasi kedua, karena efek sampingnya lebih ringan dibandingkan generasi pertama. ${ }^{18-19}$

Pada pasien demensia dengan pneumonia yang mendapat terapi antibiotik dapat dilakukan skoring prognostik untuk memperikirakan risiko kematian dalam 14 hari berdasarkan EMGO Institute for Health and Care Research. Hal ini untuk membantu dokter dalam menentukan keputusan (Tabel 2).${ }^{10}$ Skor total 0-6 berisiko sangat rendah (2\%); skor 7-11 berisiko rendah (6\%); skor 12-16 berisiko sedang (16\%); skor 17-21 berisiko tinggi (34\%); dan skor 22-31 berisiko kematian sangat tinggi ( $>50 \%)$.

\section{Proses Pengambilan Keputusan}

Pasien demensia berat akan bergantung pada pelaku rawat dalam mengambil keputusan, seperti pasangan, anak, orang tua, saudara kandung lain atau tetangga. ${ }^{20}$ Akan lebih baik jika diskusi mengenai pengambilan keputusan ini dilakukan saat demensia masih dalam tahap awal (saat kemampuan kognitif masih baik), sehingga dapat diketahui keinginan pasien untuk perawatan berikutnya. ${ }^{20}$

Di Indonesia, isu mengenai pengambilan keputusan ini diatur dalam Peraturan Menteri Kesehatan 290 tahun 2008 tentang Persetujuan Tindakan Kedokteran. Orang yang berhak memberikan persetujuan adalah pasien yang kompeten atau keluarga terdekat. Penilaian terhadap kompetensi pasien dilakukan oleh dokter saat
Table 2. Skoring Prognostik untuk Pasien Demensia Berat dengan Pneumonia

\begin{tabular}{lc}
\hline Karakteristik Pasien Saat Diagnosis & Skor \\
\hline Jenis Kelamin: & \\
- Perempuan & 0 \\
- Laki-laki & 2 \\
Laju Napas Per Menit: & \\
- $<21$ & 0 \\
- $21-30$ & 1 \\
- $31-40$ & 2 \\
- $>40$ & 3
\end{tabular}

Kesulitan Bernapas:

- Tidak ada 0

- Ada 3

Denyut Jantung Per Menit:

- $<76 \quad 0$

- 76-95 2

- 96-115 4

- $>115 \quad 6$

Penurunan Kesadaran:

- Tidak ada 0

- Ada 3

Asupan Cairan Rata-rata Seminggu Terakhir

- $\operatorname{Cukup}(\geq 1,5 \mathrm{~L} /$ hari) 0

- Tidak cukup $(<1,5 \mathrm{~L} /$ hari) 3

- Ketergantungan makan:

- Mandiri 0

- Membutuhkan bantuan 4

- Ketergantungan penuh 8

Luka Tekan:

- Tidak ada 0

- Ada 3

Skor Total 0-31

diperlukan persetujuan pada situasi tertentu, seperti penghentian/penundaan bantuan hidup. ${ }^{21}$

Saat memberikan penjelasan tersebut, dokter harus memahami nilai dan budaya pasien dan keluarganya (Gambar 1 dan 2) sambil memberikan saran medis terbaik sesuai kompetensinya. Hal ini dilakukan dengan empati dan berdasarkan bukti 


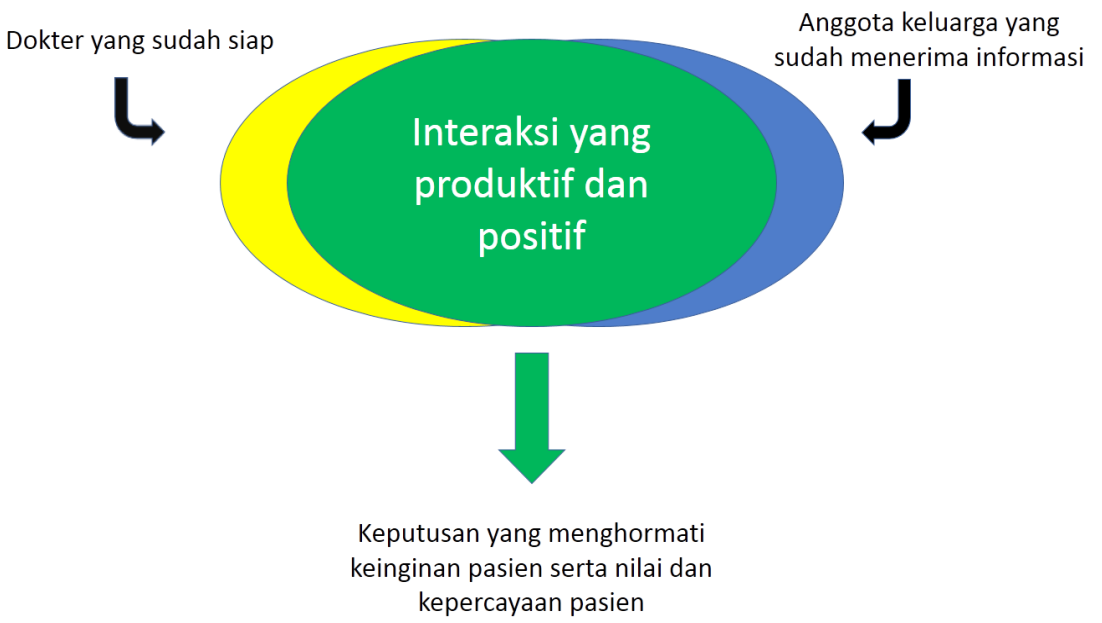

Gambar 1. Ilustrasi Ideal Pengambilan Keputusan di Akhir Kehidupan Ketika Pasien Tidak Lagi Dapat Berpartisipasi ${ }^{3}$
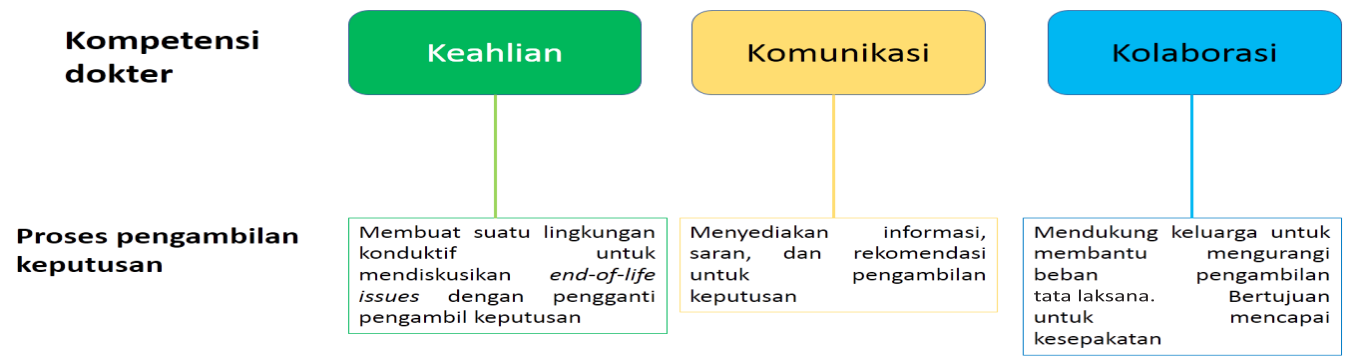

Gambar 2. Kompetensi Dokter yang Memungkinkan Proses Pengambilan Keputusan ${ }^{3}$

ilmiah untuk meminimalisasi beban pengambilan keputusan oleh pengganti pengambil keputusan (surrogate decision-maker). ${ }^{4}$

Banyak faktor yang memengaruhi pengambilan keputusan, tetapi yang paling penting adalah persepsi pengganti pengambil keputusan mengenai kualitas kehidupan pasien. Ketika pengambil keputusan menilai bahwa kualitas kehidupan pasien masih baik, keputusan yang akan diambil cenderung untuk mempertahankan nyawa pasien. Ketika persepsi mengenai kualitas kehidupan pasien dinilai buruk, pengambil keputusan akan lebih cenderung untuk merawat pasien secara simtomatik atau paliatif saja. ${ }^{4}$

\section{KESIMPULAN}

Masalah-masalah pada akhir kehidupan pasien demensia berat bukanlah masalah yang dapat ditangani sendiri oleh dokter maupun oleh keluarga pasien. Hal ini dapat dicari penyelesaian terbaiknya dengan diskusi antara tim dokter atau medis dengan keluarga pasien sebagai pengambil keputusan. Dokter tetap harus memahami nilai dan budaya yang dimiliki oleh pasien sambil tetap memberikan nasehat medis yang terbaik sesuai dengan kompetensinya.

\section{DAFTAR PUSTAKA}

1. Kemenkes RI. Lansia yang sehat, lansia yang jauh dari demensia. Kemenkes RI [serial online]. 2016 [diunduh Mei 2018]. Tersedia dari: Departemen Kesehatan RI.

2. Prince M, Guerchet M, Prina M. The epidemiology and impact of dementia: Current state and future trends. Geneva: World Health Organization. 2015. h. $1-4$.

3. Volicer L. End-of-life care for people with dementia in residential care settings. Alzheimers Dement. 2015: 761-767.

4. Arcand M. End-of-life issues in advanced dementia: Part 1: Goals of care, decision-making process, and family education. Canadian Family Physician. 2015;61(4):330-4.

5. Parker M, Power D. Management of swallowing difficulties in people with advanced dementia. Nursing Older People (through 2013). 2013;25(2):26.

6. Sampson EL, Candy B, Jones L. Enteral tube feeding for older people with advanced dementia. Cochrane Database Syst Rev. 2009 Apr 15;2(2):CD007209. 
7. Finucane TE, Bynum JP. Use of tube feeding to prevent aspiration pneumonia. The Lancet. 1996;348(9039):1421-4.

8. Dharmarajan TS, Unnikrishnan D, Pitchumoni CS. Percutaneous endoscopic gastrostomy and outcome in dementia. Am J Gastroenterol. 2001;96(9):2556.

9. Sanders DS, Carter MJ, D'silva J, James G, Bolton RP, Bardhan KD. Survival analysis in percutaneous endoscopic gastrostomy feeding: A worse outcome in patients with dementia. Am J Gastroenterol. 2000;95(6):1472-5.

10. Arcand M. End-of-life issues in advanced dementia: Part 2: Management of poor nutritional intake, dehydration, and pneumonia. Can Fam Physician. 2015;61(4):337-41.

11. Van-der-Steen JT, Ooms ME, Adèr HJ, Ribbe MW, van der Wal G. Withholding antibiotic treatment in pneumonia patients with dementia: A quantitative observational study. Arch Intern Med. 2002 Aug 12;162(15):1753-60.

12. Givens JL, Jones RN, Shaffer ML, Kiely DK, Mitchell SL. Survival and comfort after treatment of pneumonia in advanced dementia. Arch Intern Med. 2010;170(13):1102-7.

13. Gray SL, Dublin S, Yu O, Walker R, Anderson M, Hubbard RA, Crane PK, Larson EB. Benzodiazepine use and risk of incident dementia or cognitive decline: Prospective population based study. BMJ. 2016;352:i90.
14. Steinberg M, Lyketsos CG. Atypical antipsychotic use in patients with dementia: Managing safety concerns. Am J Psychiatry. 2012;169(9):900-6.

15. Rochon PA, Vozoris N, Gill SS. The harms of benzodiazepines for patients with dementia. CMAJ. 2017;189(14):E517.

16. American Geriatrics Society. 2012 beers criteria update expert panel. American Geriatrics Society updated beers criteria for potentially inappropriate medication use in older adults. J Am Geriatr Soc. 2012;60(4):616-31.

17. Tampi RR, Tampi DJ, Balachandran S, Srinivasan S. Antipsychotic use in dementia: A systematic review of benefits and risks from meta-analyses. Therapeutic advances in chronic disease. 2016;7(5):229-45.

18. Yohanna D, Cifu AS. Antipsychotics to treat agitation or psychosis in patients with dementia. JAMA. 2017;318(11):1057-8.

19. Alzheimer's A. 2015 Alzheimer's disease facts and figures. Alzheimers Dement. 2015;11(3):332-84.

20. Whitlatch CJ, Orsulic-Jeras S. Meeting the informational, educational, and psychosocial support needs of persons living with dementia and their family caregivers. The Gerontologist. 2018;58(Supl 1):S58-73.

21. Kemenkes RI. PMK nomor 290 tahun 2008 tentang persetujuan tindakan kedokteran. Jakarta; Kemenkes RI; 2008. 